\title{
Selecting graduates for the interns' award by using multisource feedback process: does it work?
}

\author{
Kathryn Strachan ${ }^{1}$, Sameer Otoom ${ }^{1}$, Amal AL-Gallaf ${ }^{1}$ and Ahmed Al Ansari 1,2,3*
}

\begin{abstract}
Background: The purpose of this study is to find a reliable method for choosing graduates for a higher-education award. One such method that has achieved notable popularity is known as multisource feedback. Multisource feedback is assessment tool that uses evaluations of different groups and includes both physicians and non-physicians. It is useful for assessing several domains, including professionalism, communication and collaboration, and therefore is a valuable tool for providing a well-rounded selection of the top interns for postsecondary awards. 16 graduates in Royal College of Surgeons in Ireland-Medical University of Bahrain (RCSI Bahrain) responded to an invitation to participate in the student award, which was conducted by the using the multisource feedback process. 5 individuals from different categories (physicians, nurses, and fellow students), rated each participant in this study. A total of 15 individuals were the proposed number for rating. The ratings were calculated using mean and standard deviation, and the award went to the one of the top score out of the 16 participants. Reliability and internal consistency was calculated using Cronbach's coefficient, and construct validity was evaluated using factor analysis.

Results: 16 graduates participated in the Royal College of Surgeons in Ireland-Bahrain interns' award based on the multisource feedback process, giving us a $16.5 \%$ response rate. The instrument was found to be suitable for factor analysis and showed 3 factor solutions representing $79.3 \%$ of the total variance. Reliability analysis using Cronbach's a reliability of internal consistency indicated that the full scale of the instrument had high internal consistency (Cronbach's a 0.98).

Conclusion: This study confirmed our hypothesis, finding multisource feedback to be a process for choosing the most suitable graduates for interns' awards that is both reliable and valid. Unfortunately, there were low response rate, which could mean that multisource feedback is not a realistic way to bring most students into the process.
\end{abstract}

Keywords: MSF, Interns, Professionalism, Communication, Collaboration

\section{Background}

Although it is a difficult task, finding a reliable method for choosing graduates for a higher-education award is far from impossible. The reason for this challenge is that the selection method should be realistic, acceptable, valid, reliable, and makes a positive difference for educational outcomes [1]. Such a reliable evaluation

\footnotetext{
*Correspondence: ahmed.alansari@bdfmedical.org; drahmedalansari@gmail.com

${ }^{2}$ Training and Education Department, Bahrain Defense Force Hospital, Off Waly Alahed Avenue, West Riffa, P. O. Box 28743, Riffa, Bahrain

Full list of author information is available at the end of the article
}

method will help to select the best candidates and will show the strengths and weaknesses of the graduates [2]. It is extremely important to prove an in-depth evaluation of medical graduates, since they are just beginning their careers in the profession. In addition to selecting the best candidates for the university award, the feedback received from these evaluations will improve educational outcomes by showing areas for individuals to focus on to strengthen their future performance [3].

Multisource feedback (MSF), which is a very popular process also known by some researchers as the $360^{\circ}$ evaluation, is an evaluation process in which various raters 
fill out surveys to evaluate their medical peers and colleagues. This evaluation process provides feedback from individuals who are not the attending and/or supervising physicians [4]. This type of assessment uses raters from a variety of groups who interact with trainees $[5,6]$.

The multisource feedback (MSF) process is seen as a particularly effective framework for evaluating physicians regarding their interactions and relationships [7]. MSF focusses on assessing different domains such as clinical skills, communication, professionalism, collaboration, and patient management $[8,9]$.

Since the MSF process is an effective, reliable, valid, and streamlined method for evaluation [10-12], we decided to use it in this study as the primary selection criteria for potential candidates to be awarded and labeled as the top university graduates. To our knowledge, this method has not previously been used to select candidates for students' awards in higher education. The aims of this study therefore were: (1) to select the best candidates among the graduates based on the MSF evaluation, and (2) to analyze the effectiveness, validity, and reliability of MSF as a process for selecting graduates who are the best fit for the university award.

\section{Methods}

We invited all of our graduates for this year-97 students - to participate in the interns' award. These potential participants were students who had completed medical school and began year-long internship rotation at different hospitals. All the interns who had finished their medical programme at RCSI Bahrain and started their first-year internship rotation were contacted by email. They were informed of the award competition and its purpose, requirements, selection criteria, and a guide for implementing the MSF process. Interns were sent an email with a form that consisted of three tables to be completed by eight nominated colleagues from each of the three different categories: interns, chief resident/consultant, and co-workers/nurses. In addition to these three categories, evaluation forms and a self-evaluation form were expected to be completed.

The nomination form entailed some details about the raters, including: position, job title, department, and email address. Only sixteen interns were interested in applying for the award and each submitted their nominees' list to an independent administrative team at RCSI Bahrain. The independent administrative team sent the evaluation forms to the raters and requested them to complete the forms and send them back. Each evaluator was given a month to complete and send the forms by e-mail or in person to the administrative team at RCSI-Bahrain. Given a sufficient period of time for completing the evaluation forms, raters who did not submit their forms were contacted, as a reminder, by means of a second email through the administrative team. The independent administrative team was responsible for distributing the instruments electronically, collecting them, anonymizing the forms using a number code for each intern, and inputting all data into Microsoft Excel Worksheet.

This study had three groups of people who rated the candidates: nurses, physicians, and student colleagues. The candidates selected eight individuals from each of these three categories, and the researchers randomly selected five out of these eight. Five members of each of these three groups were therefore responsible for rating each candidate.

\section{Instrument}

This study made use of the Bahrain Defence Force Instrument for professionalism, communication, and collaboration (BDF/PCC). It was established using several factors: the physician achievement review instrument (PAR) [12, 13]; the Maastricht list for history-taking and advice scoring instrument (MAAS-Global) [14], the Calgary-Cambridge tool, which measures communication abilities [15], the Sheffield peer review assessment tool (SPRAT) [1], the assessment of interprofessional team collaboration scale (AITCS) [16], and the opinions of specialists. The instrument focusses on the evaluation of professionalism, collaboration, and communication skills.

Previous studies were used to establish validity (face and content) for the BDF/PCC instrument [11]. It included 39 items, 15 of which measured professionalism, 13 of which to measured communication skills, and 11 of which measured collaboration. It was designed such that various groups of people, such as interns, consultants, senior medical colleagues, and coworkers, could all use it. It used a 5-point response scale, such that (1) meant "among the worst"; (2) meant "bottom half"; (3) meant "average"; (4) meant "top half"; and (5) meant "among the best". There was also an option to provide "unable to assess" (UA) as a response.

\section{Statistical analysis}

This study used several statistical analyses to answer the research questions. Mean and standard deviation were calculated for the total responses for each participant to determine who scored the highest. To ascertain the level of feasibility of the BDF/PCC instrument, we used both the rate of response and the number of responders necessary to obtain reliable results $[1,13]$.

To find the appropriate groupings of items on the survey, explanatory factor analysis was used. For each survey 
item, a factor was assigned, and it was given a loading factor equal or greater than 0.40 . Whenever an item was cross-loaded (that is, loaded on 2 or more factors), it was given to the highest among the factors it was loaded on. To determine how many factors to extract, the Kaiser rule was used (that is, eigenvalues $>1.0$ ). If an item was loaded on more than one factor (cross-loading), the item was assigned to the highest factor where it was loaded. The number of factors to be extracted was based on the Kaiser rule that eigenvalues are greater than 1.0 [17].

It was also necessary to determine how homogeneous each composite scale was. To do so, we calculated itemtotal correlations, with corrections for overlap [18]. An item was considered to measure the same construct as other composite scale items if and only if its total correlation coefficient was 0.3 or higher. We also used Pearson's correlation coefficient for estimating inter-scale correlations, to find how much the scales overlapped [19].

To determine internal consistency and reliability, Cronbach's coefficient-which is a common way of evaluating internal consistency-was used for each factor and each scale individually [18]. Next, a generalizability analysis was used to find the $\mathrm{Ep}^{2}$ and to make sure that enough questions were given and enough evaluators were used for there to be stable and accurate data for every intern. Previous studies showed that if $\mathrm{Ep}^{2}$ is 0.70 or higher, the data are stable; otherwise, there must be more items on the list or more responders in order to obtain adequate stability $[11,20]$.

\section{Responders}

The responders for this study were organized into three groups: nurses, physicians, and fellow students. In order to be eligible to be a responder, they needed to have spent at least 1 or 2 months working alongside the graduate. Participants were asked to select eight individuals from each category, and the investigators randomly chose five out of these eight individuals, so that five individuals from each of the three above-mentioned groups rated each respondent. Different interns had different numbers of observers, and this difference was determined how many raters' responses there were.

\section{Results}

Our multisource feedback process achieved a response rate of only $16.5 \%$, including 10 female and 6 male graduates. This low response rate may indicate that such a process is not ideal for use in selecting graduates for the interns' award. The participants responded to most of the questionnaire's questions.

Out of the 16 participants, the highest score was for a male graduate, who achieved 4.77 out of 5 as a mean rating. The second highest was a female whose total mean rating was 4.74 . The lowest participant scored low on all 3 domains, giving a total mean rating of 3.54 out of 5 (Table 1).

We found that the BDF/PCC instrument was suitable for factor analysis $(\mathrm{KMO}=0.895$; Bartlett test significant, $\mathrm{p}<0.00$ ). The response data from the questionnaire could therefore be decomposed into three

Table 1 Number of observers and the mean score for knowledge, professionalism, communication skills and collaboration for the interns

\begin{tabular}{|c|c|c|c|c|c|c|}
\hline Doctor ID\# & $\begin{array}{l}\text { Proposed total } \\
\text { number of observer }\end{array}$ & $\begin{array}{l}\text { Actual number } \\
\text { of observers }\end{array}$ & $\begin{array}{l}\text { Total mean } \\
\text { score }\end{array}$ & $\begin{array}{l}\text { Mean score in } \\
\text { professionalism }\end{array}$ & $\begin{array}{l}\text { Mean score in } \\
\text { communication }\end{array}$ & $\begin{array}{l}\text { Mean score } \\
\text { in collaboration }\end{array}$ \\
\hline 1. & 15 & 9 & 4.28 & 4.53 & 3.82 & 4.49 \\
\hline 2. & 15 & 14 & 4.04 & 4.02 & 4.11 & 4.00 \\
\hline 3. & 15 & 12 & 3.95 & 4.61 & 3.72 & 3.32 \\
\hline 4. & 15 & 13 & 4.74 & 4.95 & 4.67 & 4.55 \\
\hline 5. & 15 & 8 & 4.77 & 4.76 & 4.75 & 4.80 \\
\hline 6. & 15 & 9 & 4.48 & 4.71 & 4.40 & 4.27 \\
\hline 7. & 15 & 9 & 4.42 & 4.51 & 4.19 & 4.57 \\
\hline 8. & 15 & 8 & 3.78 & 4.32 & 3.51 & 3.36 \\
\hline 9. & 15 & 13 & 4.57 & 4.71 & 4.35 & 4.65 \\
\hline 10. & 15 & 12 & 4.56 & 4.70 & 4.37 & 4.61 \\
\hline 11. & 15 & 5 & 4.05 & 4.40 & 4.03 & 3.59 \\
\hline 12. & 15 & 15 & 3.54 & 3.99 & 2.98 & 3.59 \\
\hline 13. & 15 & 11 & 4.63 & 4.76 & 4.40 & 4.71 \\
\hline 14. & 15 & 15 & 4.53 & 4.47 & 4.54 & 4.61 \\
\hline 15. & 15 & 13 & 4.71 & 4.46 & 4.44 & 4.70 \\
\hline 16. & 15 & 9 & 4.24 & 4.28 & 4.20 & 4.23 \\
\hline
\end{tabular}

First quartile $(25$ th percentile $)=4.07$, second quartile $(50$ th percentile $)=4.19$, third quartile $(75$ th percentile $)=4.31$ 
factors-professionalism, communication, and collaboration-which accounted for $79.3 \%$ of the total variance.

Cronbach's $\alpha$ coefficient for reliability and internal consistency was used to determine that BDF/PCC exhibits high levels of internal consistency, with Cronbach's coefficient $\alpha$ equal to 0.98 . For the factors, or subscales, within the questionnaire, there were also high levels of internal consistency and reliability, with Cronbach's $\alpha$ coefficient greater or equal to 0.93 . We replicated a previous D study to estimate the $\mathrm{EP}^{2}$ for up to ten raters, and determined that 1 assessor resulted in an $\mathrm{EP}^{2}$ value of 0.30; 8 assessors resulted in an $\mathrm{EP}^{2}$ value of 0.78 ; and 10 assessors resulted in an $\mathrm{EP}^{2}$ value of 0.81 [20] (Table 2).

\section{Discussion}

In this study, we introduced a new method to select graduates for Medical School awards. As far as we know, no past studies have used the MSF process to choose graduates for college awards. Although this study found that MSF is a way to valid and reliable process for such a task, our low response rates mean that we cannot claim it as a feasible method.

Multisource feedback, which is also called $360^{\circ}$ evaluation, has become a widely used way to evaluate trainees across diverse fields and for various reasons [21]. Furthermore, this study found that the MSF process was a valid and reliable way to assess university students'

Table 2 Descriptive statistics, item analysis, correlated item-total correlation and exploratory factor analysis

\begin{tabular}{|c|c|c|c|c|c|c|c|c|c|}
\hline \multirow[t]{2}{*}{$\mathbf{Q}$} & & \multirow[t]{2}{*}{$\mathbf{N}$} & \multirow[t]{2}{*}{ M } & \multirow[t]{2}{*}{ SD } & \multirow[t]{2}{*}{$\%$ UA } & \multirow{2}{*}{$\begin{array}{l}\text { Correlated } \\
\text { item-total } \\
\text { correlation }\end{array}$} & \multicolumn{3}{|c|}{$\begin{array}{l}\text { Factors identified } \\
\text { by factor analysis }\end{array}$} \\
\hline & & & & & & & Colla & Comm & Profe \\
\hline Q1 & Maintains confidentiality of patients & 173 & 4.73 & 0.63 & 2.80 & 0.70 & & 0.74 & \\
\hline Q2 & Recognizes boundaries when dealing with other physicians & 174 & 4.71 & 0.68 & 2.20 & 0.71 & 0.72 & & \\
\hline Q3 & Recognizes boundaries when dealing with other health care professionals & 174 & 4.74 & 0.63 & 2.20 & 0.70 & 0.72 & & \\
\hline Q4 & Shows professional and ethical behavior & 173 & 4.80 & 0.59 & 2.80 & 0.57 & 0.71 & & \\
\hline Q5 & Is punctual, and performs tasks in a time-appropriate manner & 174 & 4.78 & 0.60 & 2.20 & 0.57 & 0.82 & & \\
\hline Q6 & $\begin{array}{l}\text { Is able to handle situations in a professional manner and exhibits self-con- } \\
\text { trol, avoiding emotional outbursts in stressful situations }\end{array}$ & 170 & 4.54 & 0.73 & 4.50 & 0.76 & & & 0.71 \\
\hline Q7 & $\begin{array}{l}\text { Respects patient's autonomy and right to be involved in his/her own } \\
\text { management }\end{array}$ & 165 & 4.73 & 0.66 & 7.30 & 0.70 & & 0.78 & \\
\hline Q8 & Is reliable and responsible when preforming his duties & 173 & 4.79 & 0.57 & 2.80 & 0.71 & 0.70 & & \\
\hline Q9 & Is honest, and handles his/her duties in a dignified manner & 173 & 4.83 & 0.55 & 2.80 & 0.77 & 0.62 & & \\
\hline Q10 & Accepts constructive criticism and develops goals for improvement & 164 & 4.59 & 0.80 & 7.90 & 0.71 & & 0.67 & \\
\hline Q11 & $\begin{array}{l}\text { Respects cultural, individual and role differences including age, gender, race, } \\
\text { religion, disability, language, sexual orientation, and socioeconomic status }\end{array}$ & 173 & 4.75 & 0.63 & 2.80 & 0.70 & & 0.76 & \\
\hline Q12 & Follows institutional policies and procedures & 176 & 4.70 & 0.66 & 1.10 & 0.51 & & 0.70 & \\
\hline Q13 & Arrives on time to scheduled appointments and hospital activities & 168 & 4.72 & 0.68 & 5.60 & 0.71 & 0.81 & & \\
\hline Q14 & Manages healthcare resources efficiently & 160 & 4.58 & 0.73 & 10.10 & 0.66 & & 0.58 & \\
\hline Q15 & Leads with respect and fair treatment of colleagues & 169 & 4.69 & 0.66 & 5.10 & 0.68 & 0.56 & & \\
\hline Q16 & $\begin{array}{l}\text { Communicates efficiently and in a clear, understandable fashion with col- } \\
\text { leagues within his/her team }\end{array}$ & 173 & 4.79 & 0.57 & 2.80 & 0.73 & & 0.57 & \\
\hline Q17 & $\begin{array}{l}\text { Communicates efficiently and in a clear, understandable, and compassion- } \\
\text { ate way with patients }\end{array}$ & 170 & 4.76 & 0.60 & 3.90 & 0.73 & & 0.62 & \\
\hline Q18 & Allows the patient to elaborate about his condition & 162 & 4.67 & 0.67 & 9.00 & 0.74 & & 0.70 & \\
\hline Q19 & $\begin{array}{l}\text { Communicates efficiently and in a clear, understandable, and compassion- } \\
\text { ate way with patient's families }\end{array}$ & 160 & 4.74 & 0.56 & 10.1 & 0.62 & & 0.56 & \\
\hline Q20 & $\begin{array}{l}\text { Communicates clearly and effectively with other healthcare workers, e.g. } \\
\text { nurses }\end{array}$ & 170 & 4.69 & 0.62 & 4.50 & 0.74 & 0.61 & & \\
\hline Q21 & $\begin{array}{l}\text { Explains what is being done for the patient during examination or proce- } \\
\text { dures }\end{array}$ & 157 & 4.67 & 0.70 & 11.8 & 0.66 & & 0.61 & \\
\hline Q22 & Communicates purpose and results of investigations to patients well & 150 & 4.65 & 0.67 & 15.7 & 0.64 & & 0.57 & \\
\hline Q23 & $\begin{array}{l}\text { Follows up appropriately and in a timely manner on patients' hospital } \\
\text { course }\end{array}$ & 160 & 4.66 & 0.69 & 10.1 & 0.66 & & & 0.69 \\
\hline Q24 & $\begin{array}{l}\text { Communicates management options to patients in a clear, understandable } \\
\text { way, taking into account the patients' opinion }\end{array}$ & 150 & 4.69 & 0.66 & 15.7 & 0.67 & & & 0.69 \\
\hline
\end{tabular}


Table 2 continued

\begin{tabular}{|c|c|c|c|c|c|c|c|c|c|}
\hline \multirow[t]{2}{*}{ Q } & & \multirow[t]{2}{*}{$\mathrm{N}$} & \multirow[t]{2}{*}{$M$} & \multirow[t]{2}{*}{ SD } & \multirow[t]{2}{*}{ \%UA } & \multirow{2}{*}{$\begin{array}{l}\text { Correlated } \\
\text { item-total } \\
\text { correlation }\end{array}$} & \multicolumn{3}{|c|}{$\begin{array}{l}\text { Factors identified } \\
\text { by factor analysis }\end{array}$} \\
\hline & & & & & & & Colla & Comm & Profe \\
\hline Q25 & $\begin{array}{l}\text { Displays empathy in dealing with patients by eye contact and verbal } \\
\text { responses }\end{array}$ & 156 & 4.72 & 0.65 & 12.4 & 0.70 & & 0.68 & \\
\hline Q26 & $\begin{array}{l}\text { Summarizes the information given for the patient in small quantities, with } \\
\text { concrete explanations, and understandable language }\end{array}$ & 155 & 4.67 & 0.65 & 12.9 & 0.66 & & & 0.74 \\
\hline Q27 & $\begin{array}{l}\text { Maintains calm in emergency situations, in order to communicate informa- } \\
\text { tion clearly to his/her seniors }\end{array}$ & 152 & 4.57 & 0.72 & 14.6 & 0.71 & & & 0.76 \\
\hline Q28 & $\begin{array}{l}\text { Communicates accurate patient information to physicians from other } \\
\text { departments when required to do so }\end{array}$ & 161 & 4.70 & 0.61 & 9.60 & 0.58 & & & 0.69 \\
\hline Q29 & Manages to work well as part of a healthcare team & 165 & 4.70 & 0.67 & 7.30 & 0.61 & 0.76 & & \\
\hline Q30 & Facilitates the learning of medical colleagues and co-workers & 159 & 4.70 & 0.68 & 10.7 & 0.59 & & 0.54 & \\
\hline Q31 & Collaborates well with nurses and other healthcare workers & 162 & 4.73 & 0.63 & 9.00 & 0.69 & 0.68 & & \\
\hline Q32 & Concerned about the safety of patients and co-workers & 166 & 4.63 & 0.69 & 6.70 & 0.70 & & & 0.55 \\
\hline Q33 & Coordinates patient care efficiently & 164 & 4.71 & 0.63 & 7.90 & 0.67 & & & 0.62 \\
\hline Q34 & $\begin{array}{l}\text { Collaborates with other healthcare workers in order to achieve optimal } \\
\text { patient care }\end{array}$ & 168 & 4.70 & 0.66 & 5.60 & 0.58 & 0.65 & & \\
\hline Q35 & Participates in a system of call in order to provide care for patients & 164 & 4.67 & 0.71 & 7.90 & 0.57 & 0.68 & & \\
\hline Q36 & Provides appropriate guidance and help to team members on regular bases & 163 & 4.63 & 0.71 & 8.40 & 0.56 & & & 0.72 \\
\hline Q37 & Takes an extra work, when appropriate, to help the team & 165 & 4.67 & 0.74 & 7.30 & 0.61 & 0.70 & & \\
\hline Q38 & $\begin{array}{l}\text { Enables the team to achieve agreements for team process and collaborative } \\
\text { completion of assignment }\end{array}$ & 162 & 4.63 & 0.72 & 9.00 & 0.62 & & & 0.67 \\
\hline Q39 & Participates fully in collaborative process and fulfilled team agreements & 167 & 4.68 & 0.68 & 6.20 & 0.68 & 0.62 & & \\
\hline
\end{tabular}

$N$ number, $M$ mean, SD standard deviation, UA unable to assess, Comm communication skills, Colla collaboration, Profe professionalism

professionalism, collaboration, and communication skills. Since few raters are required to obtain reliable evaluation, the MSF process is shown to have high feasibility; however, this feasibility is undermined by our low response rates.

Three composite scales were obtained through this study's exploratory factor analysis: professionalism, collaboration, and communication skills. Using factor analysis, it was shown that the questionnaire could be divided into three factor solutions, which accounted for a measure of total variance amounting to $79.3 \%$, which shows that the instrument has high construct validity.

The validity of the MSF process is supported by the fact that it has high levels of reliability, as well as item-total and inter-scale correlation, all within predefined limits. With such strong evidence, medical institutions may feel confident in selecting the best graduates for the award because the results obtained using the MSF process were both reliable and valid.

Our findings may be preferable to other previously used methods to select the best graduates for the university award such as letters of recommendation, honor grades, and other factors. This is because the majority of the other methods do not include direct observation of the applicants and, therefore, may be less useful indicators for particular success-predicting behaviors [22].
Our study examined a wide range of applicants' variables, such as professionalism, communication skills, and collaboration. Additionally, the use of the MSF process on its own strengthens and supports the results of the study. Other methods may be easy to use and may have encouraged many candidates to participate, but they would have uncertain reliability. The number of raters and the psychometric properties of the instruments used in the selection of graduates provide strong evidence about the quality of the selection process [23-25].

Another advantage of MSF is that if the individual being assessed believes that the process is a trustworthy and correct method of self-improvement, they will likely use it to make changes and improve in the future. This will also help graduates pay more attention to their future performance in areas requiring improvement $[3,26]$.

In a study of family physicians, it was found that $61 \%$ of the 113 participating physicians changed or planned to change their practice based on the feedback that the program director gave after the MSF process [27]. As a general rule, the results of this study show that the only ones who used the results of the feedback to work towards self-improvement were those who believed the process was correct and trustworthy [27].

One of the important limitations of this study was the low response rates, which indicate that the MSF process 
used to select the best graduates is not feasible. Future studies may be useful for further examining the MSF process's feasibility in selecting of the best interns for the university awards.

\section{Conclusion}

"This study demonstrated that the MSF tool can be used as a valid and reliable method to select candidates for students' award in higher education. The results of this study can be used by many institutions to enhance their selection methods for graduate awards. However, the low response rate seems to suggest that although the use of the MSF is promising, it may not be feasible. Therefore, to demonstrate the feasibility of this tool future studies are recommended to further examine the use of the MSF in selecting candidates for awards".

\section{Abbreviations}

MSF: multisource feedback; RCSI: Royal College of Surgeons in Ireland; BDF/ PCC: Bahrain Defence Force/Professionalism Communication Collaboration.

\section{Authors' contributions}

$\mathrm{AA}, \mathrm{KS}$ and $\mathrm{SO}$ contributed to the conception and design of the study. AG and KS worked on the data accusation. AA and KS contributed on the data analysis and interpretation of the data. AA, KS, and SO contributed on the drafting the manuscript. All authors read and approved the final manuscript.

\section{Author details}

${ }^{1}$ RCSI Bahrain, P.O. Box 15503, Adliya, Bahrain. ${ }^{2}$ Training and Education Department, Bahrain Defense Force Hospital, Off Waly Alahed Avenue, West Riffa, P. O. Box 28743, Riffa, Bahrain. ${ }^{3}$ Arabian Gulf University, Manama, Bahrain.

\section{Acknowledgements}

To Mr. Fadi Ghosen, regulatory affairs administrator for his support toward this research project. The abstract of this study has been presented in "ICHE 2016: 18th International conference on Higher Education" held in London, United Kingdom from May 23rd to 24th 2016 and the abstract was published in "International Journal of Educational and Pedagogical Science Vol: 3, No: 5, 2016".

\section{Competing interests}

The authors declare that they have no competing interests.

\section{Availability of data and materials}

The datasets produced and analyzed throughout the current study are available from the corresponding author upon request.

\section{Consent for publication \\ Not applicable.}

\section{Ethics approval and consent to participate}

The research ethics committee at the Royal College of Surgeons in IrelandBahrain approved the research. Written consent was obtained from the graduates, and the study was conducted between February 2015 and June 2015.

\section{Funding}

There was no funding for this study.

\section{Publisher's Note}

Springer Nature remains neutral with regard to jurisdictional claims in published maps and institutional affiliations.
Received: 2 March 2016 Accepted: 23 October 2017

Published online: 30 October 2017

\section{References}

1. Archer JC, Norcini J, Davies HA. Use of SPRAT for peer review of pediatricians in training. BMJ. 2005;330:1251-3.

2. Loon JM, Overeem K, Govaerts MJB, et al. The reliability of multisource feedback in competency-based assessment programs: the effects of multiple occasions and assessor groups. Acad Med. 2015;90:1093-9.

3. Wood L, Hassell A, Whitehouse A, Bullock A, Wall D. A literature review of multi-source feedback systems within and without health services, leading to 10 tips for their successful design. Med Teach. 2006;28:e185-91.

4. Druskatt $V$, Wolff S. Effects and timing of developmental peer appraisals in self-managing work groups. J Appl Psychol. 1999;84(1):58-74.

5. Edwards M, Ewen A. 360_, feedback: the powerful new model for employee assessment and performance improvement. New York: AMACOM; 1996.

6. Waldman D, Bowen D. The acceptability of 360_appraisals: a customersupplier relationship perspective. Hum Resour Manag. 1998;37(2):117-29.

7. Van der Heijden $\mathrm{BI}$, Nojhof AH. The value of subjectivity: problems and prospects for 360 degree appraisal systems. Int J Resour Manag. 2004:15(3):493-511.

8. Brinkman WB, Geraghty SR, Lanphear BP, Khoury JC, Gonzalez del Rey JAG, Dewitt TG, Britto MT. Effect of multisource feedback on resident communication skills and professionalism-a randomized controlled trial. Arch Pediatr Adolesc Med. 2007;161(1):44-9.

9. Garra G, Wackett A, Thode H. Feasibility and reliability of a multisource feedback tool for emergency medicine residents. J Grad Med Educ. 2011:3(3):356-60.

10. Donnon T, Al Ansari A, Al Alawi S, et al. The reliability, validity, and feasibility of multisource feedback physician assessment: a systematic review. Acad Med. 2014;3(89):1-6.

11. Al Ansari A, Al Khalifa K, Al Azzawi M, et al. Cross-cultural challenges for assessing medical professionalism among clerkship physicians in a Middle Eastern country (Bahrain): feasibility and psychometric properties of multisource feedback. Adv Med Educ Pract. 2015;6:509-15.

12. Lockyer JM, Violato $\mathrm{C}$, Fidler $\mathrm{H}$. The assessment of emergency physicians by a regulatory authority. Acad Med. 2006;12:1296-303.

13. Violato C, Lockyer JM, Fidler H. Assessment of psychiatrists in practice through multisource feedback. Can J Psychiatry. 2008;8:525-33.

14. Van Thiel J, Van Dalen J, Ram P. MAAS global manual 2000. Maastricht: University Press; 2003

15. Burt J, Elmore N, Campbell J, et al. Assessing communication quality of consultations in primary care: initial reliability of the Global Consultation Rating Scale, based on the Calgary-Cambridge Guide to the Medical Interview. BMJ Open. 2014:4:e004339.

16. Orchard CA, King GA, Khalili H, et al. Assessment of Interprofessional Team Collaboration Scale (AITCS): development and testing of the instrument. J Contin Educ Health Prof. 2012;1:58-67.

17. Violato $C$, Saberton $S$. Assessing medical radiation technologists in practice: a multi-source feedback system for quality assurance. Can J Med Radiat Technol. 2006;37(2):10-7.

18. Lockyer JM, Violato C, Fidler H, Alakija P. The assessment of pathologists/ laboratory medicine physicians through a multisource feedback tool. Arch Pathol Lab Med. 2009;133:1301-8.

19. Streiner DL, Norman GR. Health measurement scales: a practical guide to their development and use. Oxford: Oxford University Press; 2008.

20. Brennan RL. Generalizability theory. New York: Springer-Verlag; 2001. p. 79,441 .

21. Hawkins RE, Katsufrakis PJ, Holtman MC, Clauser BE. Assessment of medical professionalism: who, what, when, where, how, and ... why? Med Teach. 2009;31:348-61.

22. Cullen M, Reed D, Halvorsen A, et al. Selection criteria for internal medicine residence applicants and professionalism ratings during internship. Mayo Clin Proc. 2011;86:197-202. 
23. Pulito AR, Donnelly MB, Plymale M, Mentzer RM Jr. What do faculty observe of medical students' clinical performance? Teach Learn Med. 2006;18:99-104.

24. Mazor KM, Holtman MC, Shchukin Y, et al. The relationship between direct observation, knowledge and feedback: results of a national survey. Acad Med. 2011;86:S63-8.

25. Dolmans DH, Wolfhagen $\mathrm{IH}$, Heineman E, Scherpbier AJ. Factors adversely affecting student learning in the clinical learning environment: a student perspective. Educ Health (Abingdon). 2008;21:32
26. Miller A, Archer J. Impact of workplace based assessment on doctors' education and performance: a systematic review. BMJ. 2010;341:5064.

27. Sargeant JM, Mann KV, Ferrier SN, Langille DB, Muirhead PD, Hayes VM, et al. Responses of rural family physicians and their colleague and coworker raters to a multi-source feedback process: a pilot study. Acad Med. 2003;78:S42-4.

\section{Submit your next manuscript to BioMed Central and we will help you at every step:}

- We accept pre-submission inquiries

- Our selector tool helps you to find the most relevant journal

- We provide round the clock customer support

- Convenient online submission

- Thorough peer review

- Inclusion in PubMed and all major indexing services

- Maximum visibility for your research

Submit your manuscript at

www.biomedcentral.com/submit 